\title{
Colon Adenoma with Severe Dysplasia
}

National Cancer Institute

\section{Source}

National Cancer Institute. Colon Adenoma with Severe Dysplasia. NCI Thesaurus. Code C128171.

An adenoma that arises from the colon. It is characterized by the presence of severe epithelial dysplasia. 